\title{
Clinical Audit of Normal Labour at Nekhel Central Hospital of North Sinai Governorate
}

\author{
Ahmed Ali Mohammed Nasr, Ayman El Sayed El Ashmawy, Asmaa Zakaria Nabieh Omar \\ Department of Obstetrics and Gynecology, Faculty of Medicine - Al-Azhar University (Assiut), Egypt \\ *Corresponding author: Asmaa Zakaria Nabieh Omar, Mobile: (+20) 01003767717, E-Mail: asmaazakaria560@ gmail.com
}

\begin{abstract}
Background: Clinical audit is a quality improvement process that seeks to improve patient care and outcomes through systematic review of care against explicit criteria. Where indicated, changes are implemented, and further monitoring is used to confirm improvement in healthcare delivery.

Objective: This study aimed at clinical Auditing of the normal labour in the department of Obstetrics and Gynecology, Nekhel Central hospital of North Sinai Governorate.

Patients and methods: This was a cross-sectional observational study that included 200 pregnant women attending Nekhel Central Hospital for normal vaginal delivery. We compared normal labour management and performance in Nekhel Central Hospital with NICE guidelines. The study was carried out through the period from April 2020 to October 2020.

Results: During the first stage of labour, documentation of frequency of contractions was done in $90 \%$ women labour according to NICE guidelines. Also, recording pulse, temperature and blood pressure was done in $100 \%$ pregnant women. Observation of frequency of passing urine was done in $87.5 \%$ women. $75 \%$ women underwent a vaginal examination 4 hourly according to NICE guidelines. During the second stage of labour, documentation of frequency of contractions was done for $90.0 \%$ women as NICE guidelines. During the third stage of labour, general physical condition and vaginal blood loss were observed in all cases $(100 \%)$ and this meet NICE guideline.

Conclusion: There were missing of important aspects of appropriate care in Nekhel Central Hospital especially those related to appropriateness of care givers-patients interaction, safety and completeness of examinations, and appropriateness of postpartum care.
\end{abstract}

Keywords: Clinical Audit, Normal Labour, Nekhel Central Hospital, North Sinai Governorate.

\section{INTRODUCTION}

Labour now is easily defined as the act of expulsion of the fetus and placenta to the outside world through the vagina ${ }^{(1)}$. Based on current knowledge, labour is characterized by the onset of regular painful and palpable uterine contractions of progressively increasing frequency and intensity. This is associated with progressive cervical os dilatation and descent of the leading part till full dilatation and delivery of the fetus and placenta vaginally with minimal blood loss and other risks to the mother and baby ${ }^{(2)}$. The presence of changes in cervical effacement, dilation, position, consistency, and descent of the presenting part are the key indicators in identifying the stages of labour. Concomitant with the increased frequency of contractions, a patient perceives the descent of the fetus into her pelvis as lightening ${ }^{(3)}$.

Although labour is one continuous process, it is artificially divided into 1st, 2nd and 3rd stages of labour as a continuum. The first stage is the beginning of the labour process and refers to the dilatation of the cervical os from an imaginary zero to $10 \mathrm{~cm}$ full cervical dilatation. The 2 nd stage is the aspect from full cervical os dilatation to when the fetus is pushed through the dilated cervix and the vagina to the outside world. The 3rd stage is the stage from the delivery of the baby until when the placenta is fully expelled from the uterus through the vagina ${ }^{(4)}$. The process from the 1 st to the 3 rd stage is a continuum without any break. The first stage of labour is the beginning and longest stage and to a large extent determines the outcome of the labour process because commonly, a normal first stage is followed by a normal 2nd and 3rd stages of labour. Hence in current clinical practice, the management of labour virtually equates to the management of the first stage ${ }^{(\mathbf{1})}$. The pain associated with labour is a unique and complex phenomenon. Whilst typical experiences of pain tend to be associated with injury or disease, labour pain emerges during a vital and highly positive event. In fact, as the pain intensity rises, the labour is seen to be progressing normally ${ }^{(5)}$.

"Clinical audit is the process of a quality improvement, which aims to improve the quality of care provided to patients and their outcomes through regular and systematic revision of the care according to basic and standardized criteria and the application of needed change". Reviewing of care included three domains "structure, process and outcomes" which are selected and evaluated in a systematic way according to explicit criteria ${ }^{(6)}$. A quality improvement process that seeks to improve patients' care and outcomes through systematic review of care against explicit criteria and the implementation of change. Aspects of the structure, processes, and outcomes of care are selected and systematically evaluated against explicit criteria. Where indicated, changes are implemented at an individual, team, or service level and further 
monitoring is used to confirm improvement in healthcare delivery ${ }^{(7)}$.

This study aimed at clinical auditing of the normal labour in the department of Obstetrics and Gynecology, Nekhel Central Hospital of North Sinai Governorate.

\section{PATIENTS AND METHODS}

This was a cross-sectional observational study that included 200 pregnant women attending Nekhel Central Hospital for vaginal delivery. In this study, we collected our data through direct personal-patient contact, direct observation of caregivers, patient interactions and attitudes, and recording of data in special check list sheet for every patient. The study was conducted through the period from April 2020 to October 2020.

Inclusion Criteria: Patients with full-term labour that included all women who were fullfilling the following criteria: Age from $18-40$ years, gestational age: complete 37 weeks gestation- $41 \mathrm{ws}+6$ days, and true labour pain associated with cervical changes, Cervical dilation $>3 \mathrm{~cm}$.

Exclusion Criteria: Multiple gestations, fetal malformations, complicated pregnancy (hypertension, diabetes. etc...), intrauterine growth restriction or macrosomic fetuses, antepartum hemorrhage or presence of meconium-stained fluid, preterm labour, and false labour pain.

\section{Ethical consent:}

An approval of the study was obtained from Al- Azhar University Academic and Ethical Committee. Every patient signed an informed written consent for acceptance of the study. This work was carried out in accordance with The Code of Ethics of the World Medical Association (Declaration of Helsinki) for studies involving humans.

Intervention: We observed 200 cases of normal labour from the beginning of the patient's entry until her leaving. We followed what is done with her and we measured it according to the NICE Guidelines ${ }^{\left({ }^{(8)}\right.}$.

\section{All participants were subjected to the following:}

i. History taking: Patient's demographic data, patient's menstrual history, patient's obstetric history, relevant family history and present or past medical and surgical histories.

ii. Physical Examination:

1- General examination: Blood pressure, temperature, heart rate, respiratory rate, pallor, cyanosis, jaundice, and lymph node enlargement.

2- Abdominal and pelvic examination:

$>$ Abdominal inspection for: Scars, abdominal distension, caput medusa, and Striae (stretch marks).
$>$ Abdominal palpation: Superficial palpation of the abdomen, and deep obstetric palpation of the abdomen.

$>$ Auscultation of fetal heart sounds.

3- Local Examination: Vulvar examination, vaginal examination (PV), which was done to assess cervical dilation, cervical effacement, fetal head position, amniotic membrane status.

4- Investigations: Routine investigations, and ultrasound.

\section{Management:}

Auditing of normal labour consists of:

Assessment of patient in labour from time of admission till discharge from hospital according to NICE guidelines, 2014 that consists of:

1. Evaluation of patient at time of admission when patient in labour and cervix $\geq 3 \mathrm{~cm}$.

2. Intra-Partum management of :

1st stage of labour: From $3 \mathrm{~cm}$ cervical dilation till cervix is fully dilated.

2nd stage of labour: Washing the perineum and vulva with antiseptic solution. Emptying of the bladder by sterile catheter. Patients are asked to bear down during uterine contractions. Perineum is supported when the head appears at the vulva. Mouth and nose of the fetus are cleaned when head is delivered. Inspection of the neck if the cord is coiled around it and trying to split it. Delivery of the shoulders and trunk by gentle traction. The cord is massaged toward the fetus several times.

3rd stage of labour: Oxytocin administration (route and dose). Controlled cord traction. Uterine massage after delivery of the placenta every 15 min to keep the uterus contracted. Inspection of the placenta, cord and membranes. Examination of the perineum, vulva and vagina.

3. Post-natal management of mother and newborn:

Close monitoring and surveillance during first 6 hours postpartum. Maternal outcomes: maternal morbidity \& mortality. Fetal outcomes: fetal sex, weight and APGARs.

\section{Statistical analysis}

The collected data were coded, processed and analyzed using the SPSS (Statistical Package for Social Sciences) version 22 for Windows ${ }^{\circledR}$ (IBM SPSS Inc, Chicago, IL, USA). Data were tested for normal distribution using the Shapiro Walk test. Qualitative data were represented as frequencies and relative percentages. Chi square test $\left(\chi^{2}\right)$ was used to calculate difference between two or more groups of qualitative variables. Quantitative data were expressed as mean $\pm \mathrm{SD}$ (Standard deviation). Independent samples t-test was used to compare between two independent groups of normally distributed variables (parametric data). $\mathrm{P}$ value $\leq 0.05$ was considered significant. 


\section{RESULTS}

As shown in table (1), the age of studied mothers ranged from 18 to 40 years with a mean of $28.95 \pm 6.39$ years. $32 \%$ of the studied mothers' age was under 25 years, $30 \%$ of them were between $25 \&$ 30 years and $28 \%$ were between $30 \& 35$ years and $10 \%$ were between $35 \& 40$ years. $42(21 \%)$ women were average weight, $50(25 \%)$ of them were obese and 108 (54\%) of them were overweight. 108 (54\%) mothers were from rural areas. $42(21 \%)$ women were diabetic, $50(25 \%)$ of them were hypertensive. The gestational age ranged from 37 to 41 weeks with a mean of $38.67 \pm 1.36$ weeks.

It was found that $52(26 \%)$ cases were primigravida while $148 \quad(74 \%)$ cases were multigravida. $52(26 \%)$ cases were nulliparous, 36 (18\%) were para 1 and $112(56 \%)$ were multipara (para 2 or more). $82(41 \%)$ of the studied mothers experienced abortion (one time or more).

Table (1): Sociodemographic and clinical features of the studied women

\begin{tabular}{|c|c|c|c|}
\hline & & \multicolumn{2}{|c|}{$\begin{array}{l}\text { Total cases } \\
(\mathrm{N})=200\end{array}$} \\
\hline & & $\mathbf{N}$ & $\%$ \\
\hline Age (years) & $\begin{array}{l}\text { Mean } \pm \text { SD } \\
\text { Median } \\
\text { Range }\end{array}$ & \multicolumn{2}{|c|}{$\begin{array}{c}28.95 \pm 6.39 \\
29 \\
18-40 \\
\end{array}$} \\
\hline Age categories & $\begin{array}{c}<25 \text { years } \\
25-<30 \text { years } \\
30-<35 \text { years } \\
35-40 \text { years }\end{array}$ & $\begin{array}{l}64 \\
60 \\
56 \\
20\end{array}$ & $\begin{array}{l}32.0 \% \\
30.0 \% \\
28.0 \% \\
10.0 \%\end{array}$ \\
\hline Weight & $\begin{array}{c}\text { Average } \\
\text { Obese } \\
\text { Over weight }\end{array}$ & $\begin{array}{c}42 \\
50 \\
108 \\
\end{array}$ & $\begin{array}{l}21.0 \% \\
25.0 \% \\
54.0 \%\end{array}$ \\
\hline Residence & $\begin{array}{l}\text { Rural } \\
\text { Urban } \\
\end{array}$ & $\begin{array}{c}108 \\
92 \\
\end{array}$ & $\begin{array}{l}54.0 \% \\
46.0 \% \\
\end{array}$ \\
\hline Gestational age & $\begin{array}{c}\text { Mean } \pm \text { SD } \\
\text { Median } \\
\text { Range } \\
\end{array}$ & \multicolumn{2}{|c|}{$\begin{array}{c}38.67 \pm 1.36 \\
38.5(38-39.75) \\
37-41 \\
\end{array}$} \\
\hline Medical history & $\begin{array}{c}\text { No } \\
\text { DM } \\
\text { HTN }\end{array}$ & $\begin{array}{c}108 \\
42 \\
50 \\
\end{array}$ & $\begin{array}{l}54.0 \% \\
21.0 \% \\
25.0 \% \\
\end{array}$ \\
\hline Gravidity & $\begin{array}{c}\text { PG } \\
\text { II } \\
\text { III } \\
\text { IV } \\
\text { V } \\
\end{array}$ & $\begin{array}{l}52 \\
24 \\
32 \\
34 \\
58 \\
\end{array}$ & $\begin{array}{l}26.0 \% \\
12.0 \% \\
16.0 \% \\
17.0 \% \\
29.0 \% \\
\end{array}$ \\
\hline Parity & $\begin{array}{c}\text { None } \\
\text { I } \\
\text { II } \\
\text { III } \\
\text { IV }\end{array}$ & $\begin{array}{l}52 \\
36 \\
50 \\
32 \\
30\end{array}$ & $\begin{array}{l}26.0 \% \\
18.0 \% \\
25.0 \% \\
16.0 \% \\
15.0 \%\end{array}$ \\
\hline Abortion & $\begin{array}{c}\text { None } \\
\text { I } \\
\text { II } \\
\text { III } \\
\end{array}$ & $\begin{array}{c}118 \\
34 \\
36 \\
12 \\
\end{array}$ & $\begin{array}{c}59.0 \% \\
17.0 \% \\
18.0 \% \\
6.0 \% \\
\end{array}$ \\
\hline
\end{tabular}

SD: Stanard deviation, PG: Primigravida, DM: Diabetes Milletus, HTN: hypertension

Table (2) showed that documentation of frequency of contractions was done in 90\% women. Also, recording pulse, temperature and blood pressure was done in $100 \%$ pregnant women. Observation of frequency of passing urine was done in $87.5 \%$ women. $75 \%$ women underwent vaginal examination 4 hourly according to NICE guidelines. 
Table (2): Observations during the first stage of labour according to NICE guidelines for studied pregnant women

\begin{tabular}{|l|c|c|c|c|}
\hline \multirow{2}{*}{ Parameters } & \multicolumn{3}{c|}{ Total cases (N)= 200 } \\
\cline { 2 - 5 } & \multicolumn{2}{|c|}{ Done } & \multicolumn{2}{c|}{ Not done } \\
\cline { 2 - 5 } & $\mathbf{N}$ & $\mathbf{\%}$ & $\mathbf{N}$ & $\mathbf{\%}$ \\
\hline Half-hourly documentation of frequency of contractions. & 180 & $90.0 \%$ & 20 & $10.0 \%$ \\
\hline Recording pulse hourly. & 200 & $100 \%$ & 0 & $0.0 \%$ \\
\hline Recording temperature and blood pressure 4-hourly. & 200 & $100 \%$ & 0 & $0.0 \%$ \\
\hline $\begin{array}{l}\text { Observation of frequency of passing urine. } \\
\text { Offering a vaginal examination 4 hourly or if there was } \\
\text { concern about progress or in response to the woman's } \\
\text { wishes (after abdominal palpation and assessment of } \\
\text { vaginal loss). }\end{array}$ & 175 & $87.5 \%$ & 25 & $12.5 \%$ \\
\hline
\end{tabular}

Table (3) showed the management of labour in case of delay in the first stage according to NICE guidelines for studied women. Reassessment of history and examination was done in $95 \%$ women according to NICE guidelines. While, offering the woman support, hydration, and appropriate and effective pain relief, assessment of cervical dilatation and descent and rotation of the baby's head and full assessment, including abdominal palpation and vaginal examination, before a decision is made about using oxytocin all of them were done according to NICE guidelines. On the other hand, assessment of changes in the strength, duration and frequency of uterine contractions was done for 95\% women. Also, amniotomy was done for $75 \%$ women with intact membranes. Advising the woman to have a vaginal examination 4 hours after starting oxytocin in established labour was done for $97.5 \%$ of women according to NICE guidelines.

Table (3): Management of labour in case of delay in the first stage according to NICE guidelines

\begin{tabular}{|l|c|c|c|c|}
\hline \multirow{2}{*}{} & \multicolumn{3}{|c|}{ Total cases (N)= 200 } \\
\cline { 2 - 5 } & \multicolumn{2}{|c|}{ Done } & \multicolumn{2}{c|}{ Not done } \\
\cline { 2 - 5 } & $\mathbf{N}$ & $\mathbf{N}$ & $\mathbf{\%}$ \\
\hline Reassessment of history and examination. & 190 & $95.0 \%$ & 10 & $5.0 \%$ \\
\hline $\begin{array}{l}\text { Offer the woman support, hydration, and appropriate and effective } \\
\text { pain relief. }\end{array}$ & 200 & $100 \%$ & 0 & $0.0 \%$ \\
\hline Assessment of cervical dilatation. & 200 & $100 \%$ & 0 & $0.0 \%$ \\
\hline Assessment of descent and rotation of the baby's head. & 200 & $100 \%$ & 0 & $0.0 \%$ \\
\hline $\begin{array}{l}\text { Assessment of changes in the strength, duration and frequency of } \\
\text { uterine contractions. }\end{array}$ & 190 & $95.0 \%$ & 10 & $5.0 \%$ \\
\hline $\begin{array}{l}\text { Amniotomy for all women with intact membranes, after } \\
\text { explanation of the procedure and advice that it will shorten labour } \\
\text { by about an hour and may increase the strength and pain of her } \\
\text { contractions. }\end{array}$ & 150 & $75 \%$ & 50 & $25 \%$ \\
\hline $\begin{array}{l}\text { Decision about management options, including the use of } \\
\text { oxytocin. }\end{array}$ & 200 & $100 \%$ & 0 & $0.0 \%$ \\
\hline $\begin{array}{l}\text { Full assessment, including abdominal palpation and vaginal } \\
\text { examination, before a decision is made about using oxytocin. }\end{array}$ & 200 & $100 \%$ & 0 & $0.0 \%$ \\
\hline $\begin{array}{l}\text { Vaginal examination / 4 hours after starting oxytocin in } \\
\text { established labour. }\end{array}$ & 195 & $97.5 \%$ & 5 & $2.5 \%$ \\
\hline
\end{tabular}


Table (4): Management of the first stage of labour done according to NICE guidelines

\begin{tabular}{|l|c|c|c|c|}
\hline \multirow{2}{*}{} & \multicolumn{3}{|c|}{ Total cases (N)= 200 } \\
\cline { 2 - 5 } & \multicolumn{2}{|c|}{ Done } & \multicolumn{2}{c|}{ Not done } \\
\cline { 2 - 5 } & $\mathbf{N}$ & $\mathbf{\%}$ & $\mathbf{N}$ & $\mathbf{\%}$ \\
\hline Give woman as much information and explanation as she desires. & 116 & $58.0 \%$ & 84 & $42.0 \%$ \\
\hline $\begin{array}{l}\text { Facilitate good communication between caregivers, the woman } \\
\text { and her companions. }\end{array}$ & 128 & $64.0 \%$ & 72 & $36.0 \%$ \\
\hline Patient is allowed to walk. & 116 & $58.0 \%$ & 84 & $42.0 \%$ \\
\hline Rest in bed if membranes are ruptured. & 116 & $58.0 \%$ & 84 & $42.0 \%$ \\
\hline The patient is not allowed to bear down. & 166 & $83.0 \%$ & 34 & $17.0 \%$ \\
\hline $\begin{array}{l}\text { Use non-invasive, non- pharmacological methods of pain relief } \\
\text { during labour (massage, relaxation techniques, etc.). }\end{array}$ & 86 & $43.0 \%$ & 114 & $57.0 \%$ \\
\hline Pharmacological analgesics. & 14 & $7.0 \%$ & 186 & $93.0 \%$ \\
\hline Offer oral fluids throughout labour. & 166 & $83.0 \%$ & 34 & $17.0 \%$ \\
\hline
\end{tabular}

Management, giving women as much information and explanation as they desire was done for $58 \%$. Good communication between caregivers, the woman and her companions reached to 64\%. Allowing the women to walk was about $58 \%$.

Also, preventing the women from bearing down during labour was done in $83 \%$ women. $58 \%$ women were allowed to rest in bed during membrane rupture. Using non-invasive, non-pharmacological methods of pain relief during labour like massage and relaxation techniques was about $43 \%$ while using pharmacological analgesics was 7 $\%$. Offering oral fluids throughout labour reached $83 \%$ as shown in table (4).

As shown in table (5) and during the second stage of labour, documentation of frequency of contractions was done for $90.0 \%$ of women as NICE guidelines. Recording of blood pressure hourly and recording of temperature 4-hourly was done for all patients according to NICE guidelines. Observation of frequency of passing urine was done for $87.5 \%$ of women according to NICE guidelines. Offering a vaginal examination hourly for $75.0 \%$ of women was done according to NICE guidelines. Performing intermittent auscultation of the fetal heart rate was done for half patients according to NICE guidelines.

Table (5): Observations during the second stage of labour according to NICE guidelines for studied pregnant women

\begin{tabular}{|l|c|c|c|c|}
\hline \multirow{2}{*}{ Parameters } & \multicolumn{3}{c|}{ Total cases (N)=200 } \\
\cline { 2 - 5 } & \multicolumn{2}{c|}{ Done } & \multicolumn{2}{c|}{ Not done } \\
\cline { 2 - 5 } & $\mathbf{N}$ & $\mathbf{\%}$ & $\mathbf{N}$ & $\mathbf{\%}$ \\
\hline Half-hourly documentation of frequency of contractions. & 180 & $90.0 \%$ & 20 & $10.0 \%$ \\
\hline Recording blood pressure hourly. & 200 & $100 \%$ & 0 & $0.0 \%$ \\
\hline Recording temperature 4-hourly. & 200 & $100 \%$ & 0 & $0.0 \%$ \\
\hline Observation of frequency of passing urine. & 175 & $87.5 \%$ & 25 & $12.5 \%$ \\
\hline Offering a vaginal examination hourly. & 150 & $75.0 \%$ & 50 & $25.0 \%$ \\
\hline $\begin{array}{l}\text { Performing intermittent auscultation of the fetal heart rate } \\
\text { immediately after a contraction for at least 1 minute, at least every } \\
\text { 5 minutes. Palpate the woman's pulse every 15 minutes to } \\
\text { differentiate between the two heartbeats. }\end{array}$ & 100 & $50 \%$ & 100 & $50 \%$ \\
\hline
\end{tabular}

Table (6) illustrated that woman's choice for position during labour was taken in $20 \%$ of women. Providing emotional and physical support to women during labour was done in $79 \%$ of women. Also, washing the perineum and vulva with antiseptic solution was done in $87 \%$ of women. Emptying the bladder by sterile catheter was done in $75 \%$ of women. Sterile leggings \& towels applied and asking women to bear down during uterine contractions was done in all women. Perineum was supported when the head appears at the vulva in $81 \%$ of cases. Mouth and nose of the fetus were cleaned when head was delivered with inspection of the neck if the cord is coiled around it and trying to split it then delivery of the shoulders and trunk by gentle traction, all these steps were done to all women. The cord was massaged toward the fetus several times in $80 \%$ women. 
Table (6): Management of the second stage of labour done for studied pregnant women

\begin{tabular}{|l|c|c|c|c|}
\hline \multirow{2}{*}{} & \multicolumn{3}{|c|}{ Total cases (N)= 200 } \\
\cline { 2 - 5 } & \multicolumn{2}{|c|}{ Done } & \multicolumn{2}{c|}{ Not done } \\
\cline { 2 - 5 } & $\mathbf{N}$ & $\mathbf{\%}$ & $\mathbf{N}$ & $\mathbf{\%}$ \\
\hline $\begin{array}{l}\text { Support woman's choice for position during labour } \\
\text { and childbirth. }\end{array}$ & 40 & $20.0 \%$ & 160 & $80.0 \%$ \\
\hline $\begin{array}{l}\text { Provide continuous emotional and physical support } \\
\text { to woman throughout labour. }\end{array}$ & 158 & $79.0 \%$ & 42 & $21.0 \%$ \\
\hline $\begin{array}{l}\text { Vulva \& perineum are washed with antiseptic } \\
\text { solution. }\end{array}$ & 174 & $87.0 \%$ & 26 & $13.0 \%$ \\
\hline Emptying bladder by sterile catheter. & 150 & $75.0 \%$ & 50 & $25.0 \%$ \\
\hline Sterile leggings \& towels applied. & 200 & $100.0 \%$ & 0 & $0.0 \%$ \\
\hline $\begin{array}{l}\text { The patient is asked to bear down during uterine } \\
\text { contraction. }\end{array}$ & 200 & $100.0 \%$ & 0 & $0.0 \%$ \\
\hline More frequent observation of fetal heart sound. & 144 & $72.0 \%$ & 56 & $28.0 \%$ \\
\hline $\begin{array}{l}\text { Perineum is supported when the head appears at the } \\
\text { vulva. }\end{array}$ & 162 & $81.0 \%$ & 38 & $19.0 \%$ \\
\hline $\begin{array}{l}\text { Mouth and nose of the fetus are cleaned when head } \\
\text { is delivered. }\end{array}$ & 200 & $100.0 \%$ & 0 & $0.0 \%$ \\
\hline $\begin{array}{l}\text { Inspect the neck, if the cord is coiled around it, tries } \\
\text { to split it. }\end{array}$ & 200 & $100.0 \%$ & 0 & $0.0 \%$ \\
\hline Delivery of the shoulders \& trunk by gentle traction. & 200 & $100.0 \%$ & 0 & $0.0 \%$ \\
\hline The cord is massaged toward the fetus several times. & 160 & $80.0 \%$ & 40 & $20.0 \%$ \\
\hline
\end{tabular}

As shown in table (7), general physical condition and vaginal blood loss were observed in all cases (100\%) and this meet NICE guideline.

Table (7): Observations during the third stage of labour according to NICE guidelines for studied pregnant women

\begin{tabular}{|l|c|c|c|c|}
\hline \multirow{2}{*}{ Parameters } & \multicolumn{3}{c|}{ Total cases (N)=200 } \\
\cline { 2 - 5 } & \multicolumn{2}{|c|}{ Done } & \multicolumn{3}{c|}{ Not done } \\
\cline { 2 - 5 } & $\mathbf{N}$ & $\mathbf{\%}$ & $\mathbf{N}$ & $\mathbf{\%}$ \\
\hline $\begin{array}{l}\text { Observation of the general physical condition, as shown by } \\
\text { her colour, respiration and her own report of how she feels. }\end{array}$ & 200 & $100 \%$ & 0 & $0.0 \%$ \\
\hline Observation of the vaginal blood loss. & 200 & $100 \%$ & 0 & $0.0 \%$ \\
\hline
\end{tabular}

As illustrated in table (8), oxytocin administration of 10 IU IV infusion in was offered in $76 \%$ of cases and was offered by intramuscular route in $24 \%$ of cases. All pregnant women had oxytocin administration (100\%).

After cutting the cord, using controlled cord traction as a part of active management only after administration of oxytocin and signs of separation of the placenta was done in all studied cases. Recording the timing of cord clamping in both active and physiological management was done in $75 \%$ cases. Uterine massage after delivery of the placenta every 15 min was $84 \%$. Inspection of the placenta, cord and membranes and examination of the perineum, vulva and vagina were done to all patients. 
Table (8): Management of the third stage of labour according to NICE guidelines

\begin{tabular}{|c|c|c|c|c|c|}
\hline \multirow{3}{*}{\multicolumn{2}{|c|}{ Parameter }} & \multicolumn{4}{|c|}{ Total cases $(\mathbf{N})=200$} \\
\hline & & \multicolumn{2}{|c|}{ Done } & \multicolumn{2}{|c|}{ Not done } \\
\hline & & $\mathbf{N}$ & $\%$ & $\mathbf{N}$ & $\%$ \\
\hline \multirow{2}{*}{ Oxytocin administration } & 10 IU IV infusion & 152 & $76.0 \%$ & 0 & $0.0 \%$ \\
\hline & Intramuscular route & 48 & $24.0 \%$ & 0 & $0.0 \%$ \\
\hline \multicolumn{2}{|c|}{$\begin{array}{l}\text { - Do not clamp the cord earlier than } 1 \text { minute from the birth of } \\
\text { the baby unless there is concern about the integrity of the cord or } \\
\text { the baby has a heart rate below } 60 \text { beats/ minute that is not getting } \\
\text { faster. } \\
\text { - Clamp the cord before } 5 \text { minutes in order to perform controlled } \\
\text { cord traction as part of active management. } \\
\text {-If the woman requests that the cord is clamped and cut later than } \\
5 \text { minutes, support her in her choice. }\end{array}$} & 200 & $100 \%$ & 0 & $0.0 \%$ \\
\hline \multicolumn{2}{|c|}{ After cutting the cord, use controlled cord traction. } & 200 & $100 \%$ & 0 & $0.0 \%$ \\
\hline \multicolumn{2}{|c|}{$\begin{array}{l}\text { Perform controlled cord traction as part of active management } \\
\text { only after administration of oxytocin and signs of separation of } \\
\text { the placenta. }\end{array}$} & 200 & $100 \%$ & 0 & $0.0 \%$ \\
\hline \multicolumn{2}{|c|}{$\begin{array}{l}\text { Record the timing of cord clamping in both active and } \\
\text { physiological management. }\end{array}$} & 150 & $75 \%$ & 50 & $25 \%$ \\
\hline \multicolumn{2}{|c|}{$\begin{array}{l}\text { Uterine massage after delivery of the placenta every } 15 \mathrm{~min} \text { to } \\
\text { keep the uterus contracted. }\end{array}$} & 168 & $84.0 \%$ & 32 & $16.0 \%$ \\
\hline \multicolumn{2}{|c|}{ Inspection of placenta, cord and membranes. } & 200 & $100.0 \%$ & 0 & $0.0 \%$ \\
\hline \multicolumn{2}{|c|}{ Examination of the cervix, vagina, vulva and perineum. } & 200 & $100.0 \%$ & 0 & $0.0 \%$ \\
\hline
\end{tabular}

\section{DISCUSSION}

Analysis of our findings, revealed that the age of studied mothers ranged from 18 to 40 years with a mean of $28.95 \pm 6.39$ years, $42(21 \%)$ of women were average weight, $50(25 \%)$ of them were obese and 108 $(54 \%)$ of them were overweight. $108(54 \%)$ of mothers were from rural areas. $42(21 \%)$ women were diabetic and $50(25 \%)$ of them were hypertensive. The gestational age ranged from 37 to 41 weeks with a mean of $38.67 \pm 1.36$ weeks. It was found that 52 (26\%) of cases were primigravida, while $148(74 \%)$ cases were multigravida, $82(41 \%)$ of the studied mothers experienced abortion (one time or more). In agreement with our findings, the study of Eldesouky et al. ${ }^{(9)}$, which aimed to audit the current management of normal vaginal delivery at Al Azhar University Hospitals to improve emergency obstetric care? They reported that $39.3 \%$ of mothers in the study aged $<25$ years. As regards residence, about two-thirds of the mothers $(65 \%)$ were from rural areas. Regarding gravidity, $36.5 \%$ of women were gravida of 4 or more. Regarding parity, about $50 \%$ of women were Para 2 or more. About $80 \%$ of women delivered in the hospital have no abortions.

In the study on our hands, regarding the observations during the first stage of labour, documentation of frequency of contractions was done in $90 \%$ of women. Also, recording pulse hourly, temperature and blood pressure 4-hourly was done in $100 \%$ pregnant women. Observation of frequency of passing urine was done in $87.5 \%$ of women. $75 \%$ of women underwent vaginal examination 4 hourly according to NICE guidelines. This is similar to Borders et al. ${ }^{\left({ }^{10)}\right.}$ who reported that the average number of vaginal examinations for all women was 4 (range 111). Twenty-one women (10\%) had 8 or more examinations. Fifteen women had 8 vaginal examinations, 3 women had 9, 2 women had 10, and 1 woman had 11. Primiparous women averaged 5 vaginal examinations and 13 hours in labour; multiparous patients averaged 4 vaginal examinations and 6 hours in labour.

As regards management if there were delay in the first stage of labour, reassessment of history and examination was done in $95 \%$ of women according to NICE guidelines. While offering the woman support, hydration, and appropriate and effective pain relief, assessment of cervical dilatation and descent and rotation of the baby's head and full assessment, including abdominal palpation and vaginal examination, before a decision is made about using oxytocin were done to all patients according to NICE guidelines. Moreover, assessment of changes in the strength, duration and frequency of uterine contractions was done for $95 \%$ of women. Also, amniotomy was done for $75 \%$ of women with intact membranes. Vaginal examination /4 hours after starting oxytocin in established labour was done for $97.5 \%$ of women according to NICE guidelines.

Regarding the management of the first stage of labour, giving women as much information and explanation as they desire was done for $58 \%$. Good communication between caregivers, the woman and her companions reached to $64 \%$. Allowing the women 
to walk was about 58\%. Also, preventing the women from bearing down during labour was done in $83 \%$ of women. $58 \%$ of women were allowed to rest in bed during membrane rupture. Using non-invasive, nonpharmacological methods of pain relief during labour like massage and relaxation techniques was about $43 \%$, while using pharmacological analgesics was 7 $\%$. Offering oral fluids throughout labour reached 83\%. This comes in agreement with Eldesouky et al. (9) where they informing the women about their conditions (54\%). Communication between the woman and her caregivers reached to $11 \%$. Allowing the woman to walk was about $62 \%$. Also, preventing the woman from bearing down during the first stage reached to $99.7 \%$. With membrane rupture, women were allowed to rest in bed in $54 \%$ of patients. Oral fluids were given to $82 \%$ of patients during labour. On the other side, using non-invasive, nonpharmacological methods of pain relief during labour like massage and relaxation techniques was absent.

The second stage of labour was considered as the climax of the birth by the delivering woman, her partner, and the care-provider. International health policy and programming have placed emphasis on the first stage of labour, including appropriate use of the partogram and identification of hypertension or sepsis. Also, they focused on the third stage of labour with active management (AMTSL). More recently, a concerted effort to reduce perinatal losses has been made through dissemination of skills in neonatal resuscitation. However, the provision of skilled care and avoidance of complications during the second stage of labour have been relatively neglected ${ }^{(11)}$.

Regarding the observations during the second stage of labour, in the current study we revealed that documentation of frequency of contractions was done for $90 \%$ of women as NICE guidelines. Recording blood pressure hourly and recording temperature 4hourly was done in $100 \%$ pregnant women. Observation of frequency of passing urine was done in $87.5 \%$ of women and offering a vaginal examination hourly was done for $75 \%$ of women according to NICE guidelines. Performing intermittent auscultation of the fetal heart rate was done for half patients according to NICE guidelines.

Partograph must be used and completed with every woman to identify prolonged and complicated labour (for the benefit of the mother and the baby), making the decision to transfer the patient to a higher level of obstetric care, making the decision to augment labour by oxytocin, and early recognition of cephalopelvic disproportion ${ }^{(\mathbf{1 2})}$.

In our study, regarding the management of the second stage of labour, woman's choice for position during labour was taken in $20 \%$ of women. Providing emotional and physical support to women during labour was done in $79 \%$ of women. Also, washing the perineum and vulva with antiseptic solution was done in $87 \%$ of women. Emptying the bladder by sterile catheter was done in $75 \%$ of women. Sterile leggings $\&$ towels application and asking women to bear down during uterine contractions was done in all women. Perineum was supported when the head appears at the vulva was done in $81 \%$ of cases. Mouth and nose of the fetus were cleaned when head was delivered with inspection of the neck if the cord is coiled around it and trying to split it then delivery of the shoulders and trunk by gentle traction, all these steps were done to all women. The cord was massaged toward the fetus several times in $80 \%$ of women.

In our study, episiotomy was not done as it is painful, risky and not routinely recommended. Research has shown that moms seem to do better without an episiotomy, with less risk of infection, blood loss (though there is still risk of blood loss and infection with natural tears), perineal pain and incontinence as well as faster healing. Moreover, sterile leggings \& towels application and asking women to bear down during uterine contractions should be done to all women. So this is useful in the control of infection especially if episiotomy is needed or if operative delivery is done ${ }^{(13)}$.

In the present study, all interventions to reduce perineal trauma during the second stage of labour were according to NICE guidelines for studied pregnant women. In agreement with our findings, the study of Eldesouky et al. ${ }^{(9)}$ reported that woman's choice for position during labour was taken in $17 \%$ of women. As regards to emotional and physical support to women during labour, it was done in $81 \%$ of women. Also, washing the perineum and vulva with antiseptic solution was done in $98.3 \%$ of patients. Emptying the bladder by sterile catheter was done in $57.7 \%$ of patients. However, patients were asked to bear down during uterine contractions, perineum support when the head appears at the vulva, fetal mouth and nose cleaning when head was delivered with inspection of the neck if the cord is coiled around it and trying to split it then delivery of the shoulders and trunk by gentle traction, all these steps were done to all patients. More frequent observation of fetal heart sounds was done in $51.7 \%$ of patients. Finally, the cord was massaged toward the fetus several times in $74 \%$ of patients.

The third stage of labour is the time from the birth of the baby to the expulsion of the placenta and membranes. Management of the third stage is categorized into two types: Active management and physiological management ${ }^{(\mathbf{1 4})}$. Active management of the third stage involves the following components: Routine use of uterotonic drugs, deferred clamping and cutting of the cord and controlled cord traction after signs of separation of the placenta. Physiological management of the third stage involves the following components: No routine use of uterotonic drugs, no 
clamping of the cord until pulsation has stopped and delivery of the placenta by maternal effort ${ }^{(15)}$.

In the current study, regarding the observations during the third stage of labour, general physical condition and vaginal blood loss were observed in all cases $(100 \%)$ and these meet NICE guidelines.

In the present study regarding the management of the third stage of labour, oxytocin administration of 10 IU IV infusion was offered in $76 \%$ of cases and was offered by intramuscular route in $24 \%$ of cases. All pregnant women had oxytocin administration (100\%). After cutting the cord, using controlled cord traction as a part of active management only after administration of oxytocin and signs of separation of the placenta were done in all studied cases. Recording the timing of cord clamping in both active and physiological management was done in $75 \%$ of cases. Eldesouky et al. ${ }^{(9)}$ reported that usage of oxytocin during management of third stage of labour was done in $75 \%$ of cases. Oxytocin was usually given by intravenous drip in the solution (62.7\%) after delivery of the fetus to control postpartum hemorrhage. According to the American college, the response to intravenous oxytocin depends on gestational age, cervical dilatation and parity ${ }^{(\mathbf{1 6})}$.

A Cochrane review by Rabe et al. (17) demonstrated that delaying cord clamping by $30-120$ s resulted in less need for transfusion due to anemia and less intra-ventricular hemorrhage. Therefore, the residents and nurses working in the delivery room should be given instructions for cord clamping as per the NICE guidelines that all women who have active management of the third stage of labour have the cord clamped not earlier than $1 \mathrm{~min}$ from the birth of the baby and not later than $5 \mathrm{~min}$ and document the same in the patient records. This helps in reducing the neonatal complications.

\section{CONCLUSION}

A major strength of regular clinical audits is that they bring practitioners together frequently to discuss the management of severe cases and to define relevant improvement objectives appropriate to the local context and based on the audit's findings. The present clinical audit suggests that room for improvement must exist. There is a need to follow specific guidelines and treatment strategies to avert the complications during the third stage of labour.

We concluded that there are missing important aspects of appropriate care in Nekhel Central Hospital especially those related to appropriateness of caregivers-patients interaction, safety and completeness of examinations, and appropriateness of postpartum care.

\section{REFERENCES}

1. Orhue A, Aziken M, Osemwenkha A (2010): Spontaneous Latent Phase Labour: A Review of Issues in Definition, Classifications and Management Options. Trop J Obstet Gynaecol., 27 (2): 13 - 25.

2. Chukwudi O, Orhue A, Ande A (2018): Redefining Active Phase Labour: A Randomized Controlled Study of Nulliparae at Term. European Journal of Research in Medical Sciences, 6 (1): 36-48.

3. Haque J, Awal M, Islam M et al. (2018): Nurses' knowledge About Management Of Different Stages of Normal Labour in Bangladesh. The Malaysian Journal of Nursing, 9 (2): 15-19.

4. Muhunthan K (2017): Pelvic and Fetal Cranial Anatomy and the Stages and Mechanism of Labour. Best Practice in Labour and Delivery, Pp: 1-13. https://doi.org/10.1017/9781316144961.003

5. Whitburn L, Jones L, Davey M et al. (2019): Labour Pain. In Meanings of Pain. Springer, Cham., 17: 143-162.

6. Clinical Audit (2015): A manual for lay members of the clinical audit team. https://www.hqip.org.uk/wpcontent/uploads/2018/02/developing-clinical-auditpatient-panels.pdf

7. Rasheed S, Abd El-Monem A, Mohamed M et al. (2018): Management of preterm labour In Sohag University hospital: A clinical audit. Sohag Medical Journal, 22 (3): 349-356.

8. The National Institute for Health and Care Excellence (2014): Clinical Guidline 190: Intrapartum Care for Healthy Women and Babies. https://portaldeboaspraticas. iff.fiocruz.br/biblioteca /intrapartum-care-for-healthywomen-and-babies/

9. Eldesouky E, Elshahat A, Sileem S et al. (2019): Clinical Audit of Normal Labour at Al Azhar University Hospitals. Life Science Journal, 16 (11): 10-18.

10. Borders N, Robyn L, Shannon R et al. (2012): A Clinical Audit of the Number of Vaginal Examinations in Labour: A NOVEL Idea. Journal of Midwifery \& Women's Health, 57 (2):139-44.

11. Albers L, Sedler K, Bedrick E et al. (2006): Factors related to genital tracttrauma in normal spontaneous vaginal births. Birth, 33 (2):94-100.

12. Smith V, Begley C, Newell J et al. (2019): Admission cardiotocography versus intermittent auscultation of the fetal heart in low risk pregnancy during evaluation for possible labour admission-a multicentre randomised trial: the ADCAR trial. BJOG: An International Journal of Obstetrics \& Gynaecology, 126 (1): 114-121.

13. Subramaniam A, Tita A, Rouse D (2019): Obstetric Management of Labour and Vaginal Delivery. Chestnut's Obstetric Anesthesia E-Book, Pp: 393.

14. Harshitha S, Nagarathnamma R, Sailakshmi M (2019): A Clinical Audit: Intrapartum Care in Third Stage of Labour. Int J Sci Stud., 7 (2):19-23.

15. NICE Guidelines (2018): Care in the Third Stage of Labour. https://pathways. nice.org.uk/ pathways/ intrapartum-care/care-in-third-stage-of-labour

16. Bostancı E, Kilicci C, Ozkaya E et al. (2018): Continuous oxytocin versus intermittent oxytocin for induction of labour: a randomized study. The Journal of Maternal-Fetal \& Neonatal Medicine, 8: 1-6.

17. Rabe H, Reynolds G, Diaz-Rosello J (2004): Early versus delayed umbilical cord clamping in preterm infants. https://pubmed.ncbi.nlm.nih.gov/15495045/ 